\title{
Physician Payment Reform and Hospital Referrals
}

\section{Citation}

Ho, Kate, and Ariel Pakes. 2014. "Physician Payment Reform and Hospital Referrals." American Economic Review 104 (5): 200-205. https://doi.org/10.1257/aer.104.5.200.

\section{Permanent link}

http://nrs.harvard.edu/urn-3:HUL.InstRepos:37907088

\section{Terms of Use}

This article was downloaded from Harvard University's DASH repository, and is made available under the terms and conditions applicable to Open Access Policy Articles, as set forth at http:// nrs.harvard.edu/urn-3:HUL.InstRepos:dash.current.terms-of-use\#OAP

\section{Share Your Story}

The Harvard community has made this article openly available.

Please share how this access benefits you. Submit a story.

Accessibility 


\title{
Physician Payment Reform and Hospital Referrals
}

\author{
By Kate Ho AND ARIEl PAKes*
}

\footnotetext{
* Ho: Columbia University Economics Department, 1133 IAB, 420 West $118^{\text {th }}$ Street, New York, NY 10027 (e-mail: kh2214@columbia.edu). Pakes: Harvard University Economics Department, Littauer Building, Cambridge, MA 02138 (e-mail: apakes@fas.harvard.edu). We thank Mark Shepard and Anh Nguyen for their excellent research assistance. All errors are our own.
}

For over thirty years researchers have documented significant variation in medical care spending both between geographic regions and across hospitals within regions that does not seem to be related to outcomes. Much of the spending variation in the commercial insurance market is due to differences in prices across providers. ${ }^{1}$ Given the current policy focus on reducing medical care costs, these findings raise the question: what can be done to reduce the variation in prices, bringing the highest in line with the rest?

The introduction of provider payment reforms under the Patient Protection and Affordable Care Act of 2010 offers a potential answer to this question. For example, the reforms established Accountable Care Organizations (ACOs) with the initial goal of helping control the costs of the Medicare

\footnotetext{
${ }^{1}$ See for example Newhouse and Garber (2013), Coakley (2013) and Dartmouth Atlas reports such as Wennberg et al (1998).
}

program. ACOs are groups of providers whose payment arrangements are designed to give physicians a new incentive to control costs. The previous system of fee-for-service payments for Medicare services continues but in addition the ACO is eligible to share in any cost savings relative to a pre-agreed benchmark if those savings exceed some minimum level. The fraction of savings kept by the ACO is linked to performance on quality. Private ACOs are emerging in parallel to this Medicare initiative. Private ACOs have more flexibility in designing payment arrangements, but many are very similar to Medicare ACOs. In this paper we consider the impact of the incentives put in place by private ACOs on physician behavior. In particular we note that providers facing ACOtype incentives seem to refer their patients to lower-priced hospitals than other insurers. We ask what the magnitude of the savings from more widespread adoption of these incentives might be.

While little data on the impact of ACOs has emerged to date, it is possible to address these questions using information on pre-ACO markets. In particular, similar cost-control 
incentives are already applied to different extents by different commercial health insurers for their private enrollees in California. These insurers often pay large physician groups through capitation contracts under which the groups have an incentive to control hospital costs, either because they receive a fixed payment to cover the medical costs of their patients (including hospital costs), or because they share in any savings made relative to some pre-agreed benchmark for hospital costs. ${ }^{2}$

In previous papers (Ho and Pakes 2011, 2013) we analyze hospital referral choices for patients enrolled in six California health insurers that use capitation contracts to different extents. Our results indicate that patients enrolled in high-capitation insurers tend to be referred to lower-priced hospitals, all else equal, than other same-severity patients. We allow severity-specific hospital "quality" fixed effects to pick up perceived differences in hospital desirability conditional on the patient's diagnosis and severity on entry to hospital. We find that the trade-offs made

\footnotetext{
2 Under a global capitation contract the physician group is paid a fixed amount per patient to cover all costs of treating the patient (including hospital inpatient costs). Alternatively professional services capitation may be used, under which only the costs of services provided by the physician group are capitated. In about $90 \%$ of cases this type of capitation contract includes a "shared risk" arrangement, similar to the ACO "shared savings" arrangements, under which the physician group receives a share of savings made relative to a pre-agreed benchmark for hospital costs.
}

between price and this quality measure do not differ significantly across insurers. Instead high-capitation, price sensitive insurers seem to send patients longer distances to access lower-priced hospitals than other insurers with no reduction in quality.

This paper explores two implications of our estimates. First we analyze the correlates of the severity specific fixed effects that determine preferences over hospitals for different patients. We then use our estimated referral choice model to investigate the shortrun implications of applying capitation incentives more broadly. We simulate patients' hospital referrals under the scenario where a low-capitation insurer adopts the referral equation of a high-capitation insurer and predict the changes in average price paid and distance traveled under this scenario. ${ }^{3}$

\section{A Summary of our Previous Analysis}

We focus on commercially insured patients in Health Maintenance Organizations (HMOs) and analyze referral choices for women giving birth who are enrolled in the six largest insurers in the data other than Kaiser

\footnotetext{
3 For prior research on related issues see Song et al (2011) who use a difference-in-difference analysis and find reduced spending on outpatient services and improved quality of care when capitation was introduced. Colla et al (2012) conduct a similar analysis to evaluate the impact of ACO incentives for Medicare services and find little effect; though, as they note, Medicare prices are essentially fixed across providers. However the difference-in-difference method used in these papers does not allow for counterfactual analyses.
} 
Permanente. Contracts take the form of either capitation or fee-for-service arrangements between insurers and large physician groups (medical groups or Independent Practice Associations). $73 \%$ of payments made to primary physicians by the carriers we consider are capitation payments; the proportions vary across carriers from $97 \%$ for PacifiCare to $38 \%$ for Blue Cross. ${ }^{4}$

We use hospital discharge data covering all birth and delivery-related discharges from hospitals in California in the year 2003 from the state's Office of Statewide Planning and Development (OSHPD). We link this to OSHPD hospital financial data, hospital characteristics data from the American Hospital Association, and insurer financial statements from the California Department of Managed Health Care. We consider only birth and delivery-related admissions records and only private Knox Keene enrollees. ${ }^{5}$ We infer the hospital network of each insurer using the discharge data by assuming that a hospital is in the network if at least 3 patients are admitted from the particular insurer. As in Kessler and McClellan (2000), we assume that

\footnotetext{
4 The insurers, with their respective percent of payments to primary physicians that are capitated, are: Pacificare $(97 \%)$, Aetna $(91 \%)$, Health Net $(80 \%)$, Cigna (75\%), Blue Shield $(57 \%)$, Blue Cross (38\%).

5 Knox Keene plans are plans that are overseen by the California Department of Managed Health Care (DMHC) and subject to the Knox Keene Act. They are not precisely the same as HMOs. See Ho and Pakes (2013) for robustness analyses with respect to this and other issues.
}

patients consider traveling up to 35 miles to visit a general hospital and up to 100 miles to visit a teaching hospital.

We do not observe the price charged to the insurer by the hospital; instead the data includes the list price for every discharge and the average negotiated discount at the hospital level. We construct a price variable which approximates the price that the decision-maker expects the insurance company to pay for a patient entering the hospital in a given condition. It is a measure of expected list price (the average across patients in a group defined by diagnosis, age, and comorbidity information known at the time the patient is admitted to the hospital) interacted with 1 minus the average hospital discount. We then add supplemental data on the proportion of each hospital's business that comes from each insurer and use it to estimate the variation in discounts across insurers for each hospital. We use this to define a second price measure: the list price interacted with 1 minus the estimated hospital-insurer discount.

We estimate a referral equation that summarizes the trade-offs made between price, quality and patient convenience in the hospital choice. There are two estimation issues that need to be addressed. First, our price variable contains measurement error which may bias our estimates. Second, the 
price for a patient with a particular severity is likely to be correlated with the unobserved hospital quality for that severity. We control for these unobservables and for the measurement error in price by developing an estimation procedure which allows for hospital fixed effects that vary freely with severity of diagnosis and which averages out the error in prices. ${ }^{6}$ We estimate a different preference function for each insurer. Each is linear in the price paid by the insurer, the distance from the patient's home to the hospital, and a set of hospital and severityspecific dummy variables or fixed effects.

Our estimates indicate that the price coefficients are much more negative than have been found with more traditional estimation techniques (e.g. multinomial logit analyses) and are distinctly more negative the higher the capitation rate of insurers. The confidence intervals for the price coefficients for all but one insurer are ordered by decreasing percent capitation (that is, the upper bound of the confidence interval for one insurer is below the lower bound for the insurer with the nexthighest percent capitation). The one insurer, Blue Shield, is the only not for profit in the sample, and we exclude it from the remainder

\footnotetext{
6 Our severity groupings are chosen following the advice of obstetrical experts at Columbia Presbyterian Hospital.
}

of the analysis. We show that the results are robust to a number of different specifications.

We then use the price coefficients to back out bounds on the insurer, hospital, and severity specific quality terms. We find them to be highly correlated across plans: different insurers have very similar quality rankings of hospitals. We therefore add structure and estimate a model where insurers agree on the absolute quality of the hospital for each severity level but differ in the weight they place on quality in the utility equation. This allows us to represent preferences as a linear function of price, quality and distance which differs across insurers only in the coefficients of these variables. The preference function for patient $\mathrm{i}$ of insurer $\pi$ visiting hospital $\mathrm{h}$ becomes:

(1) $\mathrm{W}_{\mathrm{i}, \pi, \mathrm{h}}=\theta_{\mathrm{p}, \pi} \mathrm{p}\left(\mathrm{c}_{\mathrm{i}}, \mathrm{h}, \pi\right)+\alpha_{\pi} \mathrm{q}_{\mathrm{h}, \mathrm{s}}-\mathrm{d}\left(\mathrm{l}_{\mathrm{i}}, \mathrm{l}_{\mathrm{h}}\right)+\varepsilon_{\mathrm{i}, \pi, \mathrm{h}}$ where $p\left(c_{i}, h, \pi\right)$ is the price the insurer is expected to pay at hospital $\mathrm{h}$ for a patient who enters with condition $\mathrm{c}_{\mathrm{i}}, \mathrm{q}_{\mathrm{h}, \mathrm{s}}$ is the quality of hospital $h$ for severity $s, d\left(l_{i}, l_{h}\right)$ is the distance between the patient's home and the hospital, and $\varepsilon_{\mathrm{i}, \pi, \mathrm{h}}$ is the error term. We use this equation to examine how the trade-offs between price, quality and distance vary with capitation rates. Our findings indicate that though the price coefficient varies directly with the capitation rate, the ratio of the price coefficient to the quality coefficient does not. 
That is, the trade-off between price and quality differs extremely little across the insurers in our data. In contrast the trade-off between price and distance does differ. Highly-capitated more price-sensitive plans tend to send their patients further distances to obtain lower-priced service but do not tradeoff price against quality differently from other insurers.

\section{An Analysis of the Quality Estimates}

We now investigate the estimates of hospital quality that are uncovered in the analysis. Our model indicates that they capture all severityspecific hospital characteristics that affect the hospital choice other than price and distance traveled. We consider the (just under) 400 estimated hospital-severity specific quality terms that cover the highest-volume hospitals in the five largest markets (Los Angeles, Orange County, Inland Empire, the Bay Area, and San Diego) for the five aggregated "superseverities" defined in Ho and Pakes (2013). We take midpoints of the quality terms for which we have bounds rather than point estimates. We then add published data on hospital characteristics from the American Hospital Association survey for 2003, together with data from a 2003 survey conducted by the National Research Corporation, a healthcare market research firm, to measure amenities at California hospitals. ${ }^{7}$ After merging the three datasets and dropping observations with missing variables, we are left with 345 hospital-severity level observations.

We estimate the following regression equation:

$$
\mathrm{q}_{\mathrm{h}, \mathrm{s}}=\gamma \mathrm{X}_{\mathrm{h}}+\lambda_{\mathrm{s}}+\lambda_{\mathrm{m}(\mathrm{h})}+\varepsilon_{\mathrm{h}, \mathrm{s}}
$$

where $X_{h}$ are hospital characteristics and $\left(\lambda_{\mathrm{s}}\right.$, $\left.\lambda_{\mathrm{m}(\mathrm{h})}\right)$ are super-severity and market fixed effects respectively. The estimates are provided in Table 1. The first column constrains the impact of hospital characteristics to be fixed across severities. In the second column we interact each hospital characteristic with an indicator for the first super-severity and another that includes all other super-severities. Super-severity 1 contains the $55 \%$ of patients who have a rank 1 (routine) principal diagnosis, rank 1 comorbidities and are in the youngest age category (aged under 40). This specification allows each characteristic to have a differential effect on perceived quality for less-sick patients. The estimates indicate that

\footnotetext{
7 This is an annual survey of California households; responses are weighted according to household characteristics to ensure their representativeness within the state. We use a variable that reports the weighted number of respondent households who named a particular hospital as their first choice for best accommodations or amenities. This variable was also used in Goldman and Romley (2008). We take the weighted number of responses for each hospital and translate it to a market-level percentage: the percent of weighted respondents in the market who cited the particular hospital as having the best accommodations or amenities. We thank the National Research Corporation for providing the data.
} 
our measure of hospital quality is associated with offering a neonatal intensive care unit, being a not-for-profit institution, and having positive patient perceptions of quality of amenities. The interactions with severity fixed effects suggest that all three characteristics matter more for sicker than for less-sick patients. Notice that just under half of the variation of our severity-specific hospital quality measures is not accounted for by these characteristics (despite the fact that we include both market and super-severity fixed effects). This illustrates the need for hospital- and detailed severity-specific fixed effects in our main analysis.

\section{[ Insert Table 1 Here ]}

\section{Counterfactual Analysis}

We now consider what would happen if a low-capitation insurer adopted the preferences of a high-capitation insurer but held its hospital networks and enrollees constant. Note that we are calculating a "short-run" response. Over the longer run we would expect capitation incentives to affect the networks chosen and the premiums, and therefore perhaps the characteristics of each insurer's enrollees.

Specifically, we consider the patients of the lowest-capitation insurer in our data, Blue
Cross. We assume that increasing the proportion of payments to Blue Cross physicians that were capitated to the level of another, higher-capitation insurer in our data would imply changing Blue Cross's utility equation to that of the other insurer (holding hospital networks fixed). We simulate Blue Cross patients' hospital referrals when the preferences of other insurers are imposed. We summarize the increase in distance traveled for these patients and the associated change in price paid and hospital quality encountered.

The estimated coefficients from equation (1) suggest that high-capitation insurers place a more negative weight on price relative to distance than do other insurers, but that the weight placed on price relative to quality is essentially the same for all insurers. This suggests that, as we change Blue Cross's utility equation to that of higher-capitation insurers, we should predict an increase in distance traveled with an accompanying reduction in price. The results, reported in Table 2, are consistent with this intuition. We find that the average distance traveled to hospital for Blue Cross patients increases by between 2.5 and 6 miles (from a baseline predicted average of 4 miles) under the counterfactual arrangement. The average price paid falls by between $4.5 \%$ and $5.5 \%$ (expressed as a percentage of the average 
predicted Blue Cross price of \$3662). There is no corresponding reduction in quality. Thus the move to more widespread capitation generates a substantial cost reduction for the average patient, at the cost of some reduced convenience but no reduction in quality.

\section{[ Insert Table 2 Here ]}

\section{Discussion and Conclusion}

There are three caveats to this analysis. We consider only birth episodes; referral choices may be more or less responsive to financial incentives for other diagnoses, particularly those where physicians have more discretion over treatment choice. We hold insurers' hospital networks and their enrollees fixed in this analysis. In reality both networks and enrollees are endogenous to the supply side of the model and may change in tandem with physician incentives. We also note that there is a possible selection issue: physicians who are willing to refer patients to low-priced hospitals may select into physician groups that have contracts with high-capitation insurers. In that case our assumption that increasing capitation payments to the level of PacifiCare would change Blue Cross preferences to those of PacifiCare may be incorrect. On the other hand, in the longer term, a large-scale move to capitation contracts may prompt doctors to become more price-responsive and this might affect our results in the opposite direction.

Our findings indicate that shared savings arrangements like those being introduced for Accountable Care Organizations (ACOs) under the Patient Protection and Affordable Care Act are likely to generate cost savings and an accompanying decrease in convenience but no reduction in quality of care.

Our analysis also has implications for the structure of ACOs. Our counterfactuals assume that physicians (with the input of patients) have a free choice of hospitals within the existing networks observed in the data. In reality this may not be the case for all ACOs. Of approximately 430 ACOs formed by January 2013 , just under 50\% were integrated with a hospital system, with most of the remainder being sponsored by physician groups. If an ACO includes member hospitals, physicians in the organization may well have some incentive to refer patients to hospitals within the ACO rather than to non-member hospitals. This would limit the cost savings generated through the mechanism we study, offsetting the beneficial effects of hospitalphysician integration. Our results suggest that this may be an important input into decisions regarding the structure of ACOs. 


\section{REFERENCES}

Coakley M. 2013. "Examination of Health Care Cost Trends and Cost Drivers." Report for Annual Public Hearing under G.L.c. 6D. Colla C, Wennberg DE, Meara E, Gottlieb D, Lewis VA, Snyder CM and ES Fisher. 2012. "Spending Differences Associated With the Medicare Physician Group Practice Demonstration". Journal of the American Medical Association 308(10): 1015-1023.

Goldman D. and J. Romley. 2008. "Hospitals as Hotels: The Role of Patient Amenities in Hospital Demand". NBER Working Paper 14619.

Ho K. and A. Pakes. 2011. "Do Physician Incentives Affect Hospital Choice? A Progress Report". International Journal of Industrial Organization, 29: 317-322.

Ho K. and A. Pakes. 2012. "Hospital Choices, Hospital Prices and Financial Incentive to Physicians". Mimeo, Harvard University.

Newhouse JP. (chair) and A. Garber (ViceChair). 2013. "Variation in Health Care Spending: Target Decision Making, Not Geography". Institute of Medicine.

Song ZS, Safran DG, Landon BE, He Y, Ellis RP, Mechanic RE, Day MP and M. Chernew. 2011. "Health Care Spending and Quality in Year 1 of the Alternative Quality Contract". The New England Journal of Medicine, 365(10): 909-918.
Wennberg JE. and M. Cooper. 1998. "The Dartmouth Atlas of Health Care in the United States". Dartmouth Medical School. 
Table 1: Regression of Quality Terms on Observed Characteristics

\begin{tabular}{|c|c|c|c|c|}
\hline & \multicolumn{2}{|c|}{ Model 1} & \multicolumn{2}{|c|}{ Model 2} \\
\hline & Coefft & S.E. & Coefft & S.E. \\
\hline $\mathrm{NICU}$ & $0.21^{* *}$ & $(0.09)$ & & \\
\hline Teaching & 0.16 & $(0.27)$ & & \\
\hline Nurses per bed & 0.06 & $(0.16)$ & & \\
\hline For profit & $-0.24^{* *}$ & $(0.13)$ & & \\
\hline Patient perceptions & $0.03^{* *}$ & $(0.01)$ & & \\
\hline $\mathrm{NICU}^{*}$ severe & & & $0.20^{* *}$ & $(0.10)$ \\
\hline NICU*not severe & & & 0.27 & $(0.19)$ \\
\hline Teaching*severe & & & 0.21 & $(0.31)$ \\
\hline Teaching*not severe & & & -0.05 & $(0.54)$ \\
\hline Nurses*severe & & & 0.09 & $(0.17)$ \\
\hline Nurses*not severe & & & -0.02 & $(0.34)$ \\
\hline $\mathrm{FP}^{*}$ severe & & & $-0.24^{*}$ & $(0.14)$ \\
\hline $\mathrm{FP}^{*}$ not severe & & & -0.26 & $(0.20)$ \\
\hline Patient*severe & & & $0.03^{* *}$ & $(0.01)$ \\
\hline Patient*not severe & & & 0.02 & $(0.01)$ \\
\hline Market F.E.s & Yes & & Yes & \\
\hline Super-severity F.E.s & Yes & & Yes & \\
\hline$N$ & 345 & & 345 & \\
\hline$R^{2}$ & 0.569 & & 0.573 & \\
\hline
\end{tabular}

Notes: Regression of estimated quality terms on hospital characteristics. See Section 2 for details. **: Significant at the 5 percent level. *: Significant at the 10 percent level.

Table 2: Results of Counterfactual Analysis

\begin{tabular}{|c|c|c|c|c|c|c|c|c|c|}
\hline & \multirow{2}{*}{$\begin{array}{c}\text { Perc } \\
\text { capitn }\end{array}$} & \multicolumn{2}{|c|}{ Pred. Distance } & \multicolumn{2}{|c|}{ Pred. Price } & \multicolumn{2}{|c|}{$\Delta$ distance } & \multicolumn{2}{|c|}{$\Delta$ price } \\
\hline & & Mean & S.E. & Mean & S.E. & Mean & S.E. & Mean & S.E. \\
\hline Blue Cross & 0.38 & 3.94 & 0.08 & $\$ 3662$ & $\$ 17$ & & & & \\
\hline Pacificare & 0.97 & 10.01 & 0.12 & $\$ 3485$ & $\$ 16$ & 6.07 & 0.10 & $-\$ 178$ & $\$ 9.58$ \\
\hline Aetna & 0.91 & 7.48 & 0.11 & $\$ 3456$ & $\$ 16$ & 3.55 & 0.08 & $-\$ 207$ & $\$ 8.38$ \\
\hline Health Net & 0.80 & 6.54 & 0.10 & $\$ 3492$ & $\$ 16$ & 2.61 & 0.07 & $-\$ 171$ & $\$ 7.81$ \\
\hline Cigna & 0.75 & 4.13 & 0.08 & $\$ 3635$ & $\$ 17$ & 0.19 & 0.01 & $-\$ 27$ & $\$ 3.20$ \\
\hline
\end{tabular}

Notes: Predicted distance traveled (miles) and price paid (\$) for Blue Cross patients under estimated preference equation for each insurer. $\Delta$ distance and $\Delta$ price $=$ ave changes in these variables when move from $\mathrm{BC}$ to other-insurer preferences. Positive change = increase when move away from $\mathrm{BC}$ preferences. 